\title{
Treatment of chronic rhinosinusitis and its effects on asthma
}

\author{
S. Ragab*, G.K. Scadding ${ }^{\#}$, V.J. Lund ${ }^{\#}$ and H. Saleh"
}

ABSTRACT: The effects of rhinosinusitis treatment upon asthma are disputed.

The first randomised prospective study of surgical compared with medical therapy of chronic rhinosinusitis in $\mathbf{9 0}$ patients with and without nasal polyps was previously reported. Asthma symptoms, control, forced expiratory volume in one second (FEV1), peak flow, exhaled nitric oxide, medication use and hospitalisation at 6 and 12 months from the start of the study were also monitored. This paper reports these results in $\mathbf{4 3}$ of those patients with concomitant asthma.

Both medical and surgical treatment of chronic rhinosinusitis were associated with subjective and objective improvements in asthma. Overall asthma control improved significantly following both treatment modalities, but was better maintained after medical therapy, where improvement could also be demonstrated in the subgroup with nasal polyps. Medicine was superior to surgery with respect to a decrease in exhaled nitric oxide and increase in FEV 1 in the polyp patients. Two patients noted worsening of asthma post-operatively.

Improvement in upper airway symptoms, as assessed using a visual analogue scale, correlated with improvement in asthma symptoms and control. Treatment of chronic rhinosinusitis, medical or surgical, benefits concomitant asthma; that associated with nasal polyposis benefits more from medical therapy.

KEYWORDS: Asthma, chronic rhinosinusitis, endoscopic sinus surgery, exhaled nitric oxide, forced expiratory volume in one second, nasal polyps

$\mathbf{R}$ hinosinusitis coexisted with asthma in $34 \%$ of patients in one study [1]. Radiological studies have shown abnormal sinus radiographs in 53\% [2, 3] and mucosal thickening on sinus computed tomography (CT) scans in $74 \%$ [4] of patients with asthma. Recently, $>84 \%$ of CT scans were found to be abnormal in severe asthma, with a correlation between the extent of CT changes, sputum eosinophilia and pulmonary function [5].

A number of authors have investigated the effect of surgical treatment of rhinosinusitis upon asthma, with improvement [6-8], worsening [9, $10]$ and equivocal effect $[11,12]$ being reported. Only two studies of medical chronic rhinosinusitis (CRS) treatment exist, one included four medical patients [13], whereas the other considered CRS with polyposis alone and was nonrandomised [14].

\section{MATERIALS AND METHODS}

Patients were recruited over 2 yrs from the Rhinology Clinics of the Royal National Throat, Nose and Ear Hospital (London, UK). The study was approved by the Ethics Committee of the Royal Free Hospital (London, UK). After application of exclusion criteria, the study was discussed with 327 consecutive patients with a primary diagnosis of CRS. Of these, 90 patients who agreed to the process of randomisation were finally included and were randomised equally into the medical and surgical groups. The study design and flow chart showing the course of the study are presented in figures 1 and 2, respectively. Diagnosis of CRS was based on the criteria described by the Staging and Therapy Group [15]. The criteria for diagnosis of asthma were: 1) reversible airway obstruction that varied markedly, both spontaneously and with treatment; 2) intermittent experience of wheeze (usually worse on expiration and characteristically relieved by inhaled $\beta_{2}$-agonists), cough (usually unproductive), shortness of breath (not always associated with wheeze) and chest tightness; 3) the possibility of being triggered by a number of factors, including allergens, irritants, physical factors, emotions, occupational agents, food additives, changes in the weather, endocrine factors and upper respiratory tract viral infections; and 4) a reduction in forced expiratory volume in one second (FEV1; absolute value and/ or percentage of predicted value) and/or peak expiratory flow (PEF) during the attacks [16].
AFFILIATIONS

*Tanta University Hospitals, Tanta, Egypt.

${ }^{\#}$ Royal National Throat, Nose and Ear Hospital, and,

'Charing Cross Hospital, London, UK.

CORRESPONDENCE

G.K. Scadding

Royal National TNE Hospital

London

WC1X 8DA

UK

Fax: 442079151674

E-mail: g.scadding@ucl.ac.uk

Received:

April 122005

Accepted after revision:

February 152006

SUPPORT STATEMENT

This study formed part of the doctoral thesis of $\mathrm{S}$. Ragab, presented to the University of London (London, UK) in 2002. 
The exclusion criteria included pregnancy, lactation, significant psychological problems, inability to comply with the study protocol, children aged $<18$ yrs, acute upper or lower respiratory tract infections within 2 weeks, use of systemic corticosteroids within 4 weeks prior to the inclusion visit, systemic diseases preventing participation in the study and medical and/or surgical treatments influencing the study.

The whole study comprised 90 patients (45 males and 45 females) with CRS with a mean \pm SD age of $43 \pm 13$ yrs. Of these, 55 had CRS without polyposis and 35 CRS with polyposis. Forty-nine yielded positive skin-prick test results ( 25 treated surgically and 24 medically) and 43 were asthmatics (23 assigned to surgery), three of whom were aspirin-sensitive (two treated surgically).

The present study reports the results in the subgroup of 43 asthmatic patients with CRS with and without nasal polyposis.

\section{Subjective assessment}

Patients were asked about their nasal symptoms using a validated visual analogue scale. Patients were also requested to report any chest symptoms. Asthma symptoms were graded as follows. 0: no symptoms; 1: symptoms present but causing little or no discomfort; 2: symptoms present and troublesome but not causing interference with either daily activities or sleep; 3: symptoms present, troublesome and interfering with either daily activities or sleep; and 4: symptoms intolerable.

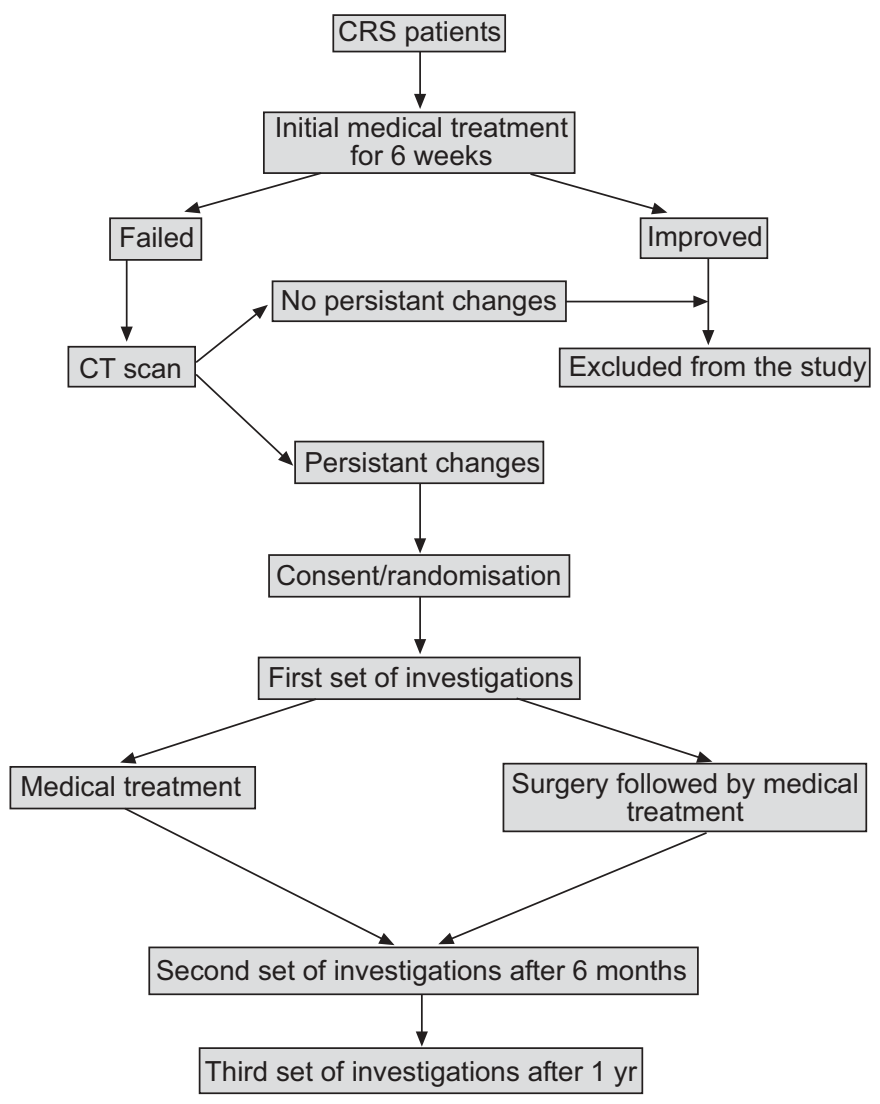

FIGURE 1. Study design. CRS: chronic rhinosinusitis; CT: computed tomography.
Conversely, overall asthma control, according to Global Initiative for Asthma guidelines [17], was scored as follows. 0: not controlled; 1 : slightly controlled; 2 : adequately controlled; 3: well controlled; and 4: very well controlled.

\section{Objective sinonasal evaluation}

A complete nasal examination, including diagnostic nasal endoscopy, was performed in all patients, who were then categorised as having polypoid or non-polypoid CRS.

Nasal nitric oxide was evaluated using a nitric oxide (NO) gas analyser (Model LR2000; Logan Research, Rochester, UK) with the sampling flow rate adjusted to $250 \mathrm{~mL} \cdot \mathrm{min}^{-1}$ [18]. The value of the last plateau part of the nasal NO trace was recorded. The mean of three recordings was used as the estimate of the nasal NO level.

\section{Objective lower airway evaluation}

Exhaled NO (eNO) was measured using the same LR2000 analyser. The patient was asked to take a deep inspiration and then exhale slowly and steadily through the mouthpiece, keeping $80 \%$ of the bio-feedback indicator lighting on in order to attain a constant exhalation flow rate of $200 \mathrm{~mL} \cdot \mathrm{s}^{-1}$ and maintain a mouth pressure of $\sim 5 \mathrm{cmH}_{2} \mathrm{O}$, as recommended by the European Respiratory Society task force [19].

Respiratory function tests, including FEV1 (\% predicted), forced vital capacity/FEV1 (\%) and PEF, were evaluated using a spirometer (Model Vitalograph 2160; Vitalograph, Maids Moreton, UK). The spirometric standards used complied with European Respiratory Society recommendations [20].

\section{Medical treatment}

Initial medical treatment

The initial medical treatment included a 6-week regimen of Dexa-Rhinaspray Duo (DRS; Boehringer Ingelheim, Bracknell, UK) and an alkaline nasal douche. DRS was delivered as two puffs into each nostril twice daily, with each metered dose containing $20 \mu \mathrm{g}$ dexamethasone-21-isonicotinate and $120 \mu \mathrm{g}$ tramazoline hydrochloride. The alkaline nasal douche powder was prepared in a 1:1 mixture of sodium chloride and sodium bicarbonate. The douche was also used twice daily $15 \mathrm{~min}$ after the DRS. Patients with positive skin-prick test result, plus a relevant history, were given allergen avoidance advice. All patients were advised to decrease exposure to pollutants such as cigarette smoke.

Medical treatment for the medically randomised group All patients received a 12-week course of erythromycin, alkaline nasal douche and intranasal corticosteroid preparations. Erythromycin was prescribed orally at $500 \mathrm{mg}$ b.i.d. for 2 weeks, followed by $250 \mathrm{mg}$ b.i.d. for 10 weeks. The alkaline nasal douche was prepared and used as instructed above. Intranasal corticosteroid preparations, in CRS patients without polyposis, were given as DRS, two puffs into each nostril b.i.d. for 2 weeks, followed by $100 \mu \mathrm{g}$ (two sprays) fluticasone propionate into each nostril b.i.d. for 10 weeks. Conversely, patients suffering CRS with polyposis received a 12-week course of $200 \mu \mathrm{g}$ (six drops) fluticasone propionate into each nostril b.i.d. In addition, three CRS patients with polyposis were prescribed a 9-day course of oral prednisolone tablets (30 mg for 3 days, $20 \mathrm{mg}$ for 3 days and $10 \mathrm{mg}$ for 3 days) after 


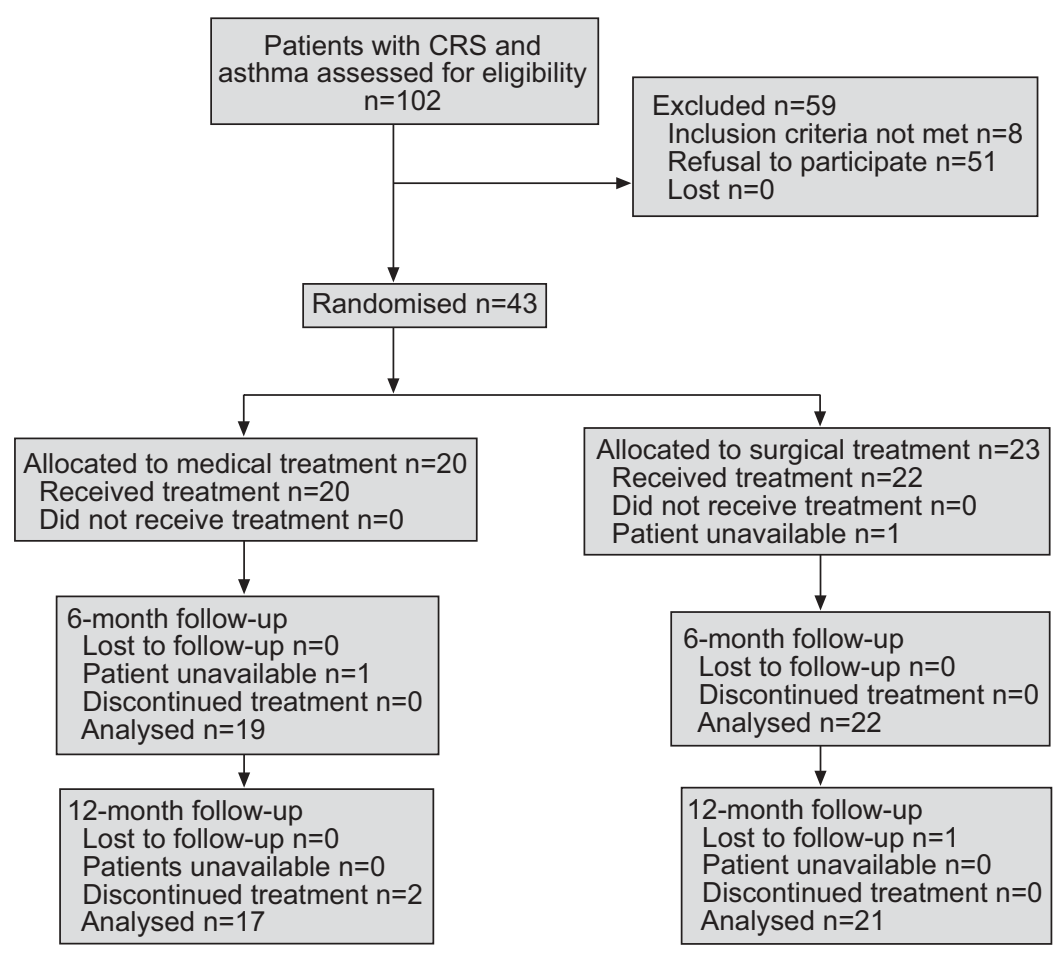

FIGURE 2. Flow chart showing course of study. CRS: chronic rhinosinusitis.

failure of the above regimen to control their manifestations. Subsequently, the use of intranasal corticosteroid preparations was tailored to the patient's clinical course, with most patients maintained on $400 \mu \mathrm{g}$ fluticasone propionate drops daily.

\section{Surgical treatment}

Endoscopic sinus surgery was performed in all patients following the Messerklinger/Stammberger technique [21] under general anaesthesia. The extent of the procedure was tailored to the extent of sinus disease, as documented by nasal endoscopy and CT scan findings. A microdebrider was used in some cases of CRS with grade 2 and 3 polyposis. At the end of the procedure, a piece of Telfa was inserted into the ethmoidal cavity and taken out on the following day. Operative findings and complications were recorded.

\section{Medical treatment after surgery}

Following endoscopic sinus surgery, all patients were prescribed a 2-week course of $500 \mathrm{mg}$ erythromycin, DRS and alkaline nasal douche b.i.d. This was followed by a 3-month course of $100 \mathrm{mg}$ (two sprays) fluticasone propionate intranasal spray into each nostril and alkaline nasal douche b.i.d. Subsequently, the use of intranasal corticosteroid preparations was tailored to the patient's clinical course, with most patients receiving two puffs of fluticasone propionate in each nostril once daily.

\section{Statistical methods}

In order to maintain equal treatment numbers in both groups, randomisation was performed using random blocks, with both patient and investigator unaware of the group assignment. A sample size of 66 patients was calculated using a two-sided Wilcoxon two-sample test at the $5 \%$ level of significance to give the study a statistical power of $80 \%$. The primary end-point was the visual analogue scale for CRS. However, it was decided to recruit 90 patients in order to raise the power of the study and compensate for any lost to follow-up. Data are presented as mean $\pm \mathrm{SD}$. A p-value of $<0.05$ was considered significant. Parametric tests, such as the paired t-test, twosample t-test and ANOVA, were applied for data that followed or were transformed to a normal distribution. Either logarithmic or square transformation was attempted in order to normalise the distribution so as to allow the use of parametric tests. Nonparametric tests, such as the Mann-Whitney U-test, Wilcoxon signed-rank test, sign test, Chi-squared test and Kruskal-Wallis test, were applied for data that did not follow a normal distribution.

\section{RESULTS}

\section{Baseline data}

No significant difference between the medical and surgical groups was found in the baseline data for any of the following: demographic characteristics, visual analogue scale, nasal NO, saccharin clearance time, chest score, use of medications, number of hospitalisations for asthma, overall asthma control score, eNO, FEV1 (\% pred) and PEF.

The patients who declined the study were not significantly different from those who took part.

\section{Chronic rhinosinusitis parameters}

Both medical and surgical treatment of CRS yielded significant improvements in almost all of the subjective and objective parameters of CRS $(\mathrm{p}<0.01)$, with no significant difference being found between the medical and surgical groups $(p>0.05)$, except for total nasal volume in the CRS $(p<0.01)$ and CRS without polyposis $(\mathrm{p}<0.01)$ groups, in which surgical 
treatment demonstrated greater increases. These results have previously been published [22].

\section{Overall asthma control score}

The improvement in the surgical group was significant, with decreasing significance from the $6-(p<0.01)$ to 12 -month $(\mathrm{p}<0.05)$ scores (table 1$)$. The medical group showed a constant significant improvement in the total group $(\mathrm{p}<0.01)$, as well as in the CRS with polyposis subgroup $(p<0.05)$. No significant difference was detected between the 6- and 12month overall asthma control scores ( $p>0.05$ (sign test)). Differences between the medical and surgical groups were insignificant ( $\mathrm{p}>0.05$ (Mann-Whitney test)).

Asthma control improvement correlated with improvement in visual analogue scores for the upper airway $(p=0.003$ (Kendall's tau- $b$ test)).

\section{Asthma symptom score}

There was a trend for improvement in asthma scores in both groups; this reached significance only in the medically treated group, in which patients reported either improvement or no change. The surgical group contained variable responses. One patient with non-polypoid CRS developed new asthma 3 months post-operatively, whereas another with polyps reported that their asthma after surgery was worse than ever before. However, the only patient reporting highly improved asthma received surgery for non-polypoid CRS. No significant difference was observed between the 6- and 12-month scores $(p>0.05$ (sign test)). Differences in the chest scores between the medical and surgical groups were insignificant $(p>0.05$ (Mann-Whitney test)).

There was a correlation between asthma score improvement and visual analogue score changes for the upper airway $(\mathrm{p}=0.005)$.

\section{Medication use}

Bronchodilator inhalers

There was a decrease in the mean use of bronchodilator inhalers in both groups. One patient reported an increase in bronchodilator use following polyp surgery. Although changes within the medical groups tended to reach greater significance, differences between surgical and medical groups were insignificant ( $\mathrm{p}>0.05$ (Mann-Whitney test)).

\section{Corticosteroid inhalers}

Changes in the use of corticosteroid inhalers attained no significance ( $p>0.05$ (sign test)) in either group.

Systemic corticosteroids for asthma

In the surgical group, 10 short courses of systemic corticosteroid therapy were required in the 12 months before surgery,

TABLE 1 Changes in overall asthma control score in chronic rhinosinusitis patients

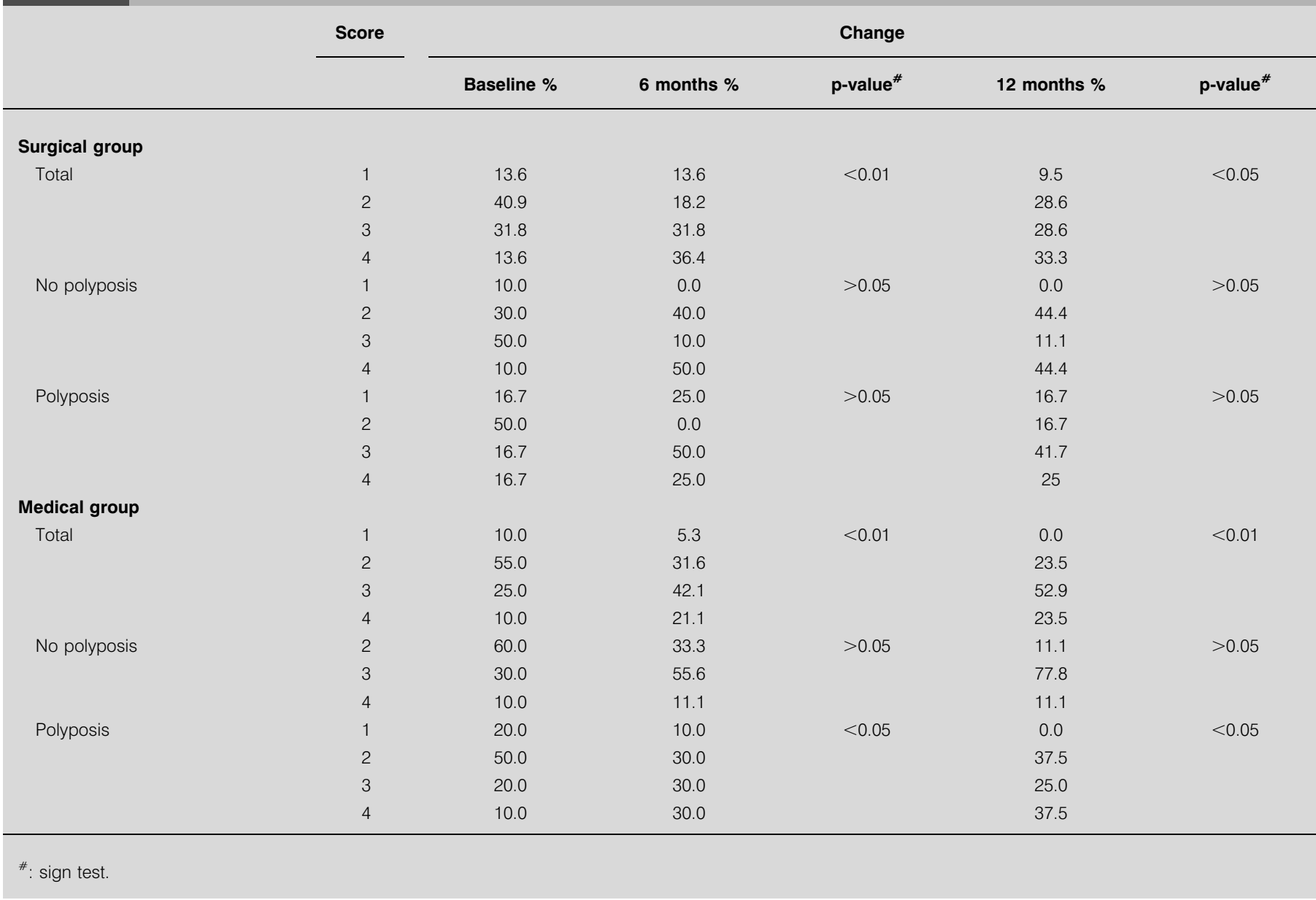


whereas only four courses were needed post-operatively $(\mathrm{p}<0.05$ (Wilcoxon signed-rank test)). The medical treatment of CRS also reduced the need for systemic corticosteroid therapy from seven courses to one $(\mathrm{p}<0.05$ (Wilcoxon signedrank test)). No significant difference was found between the surgical and medical groups ( $p>0.05$ (Mann-Whitney test)).

\section{Number of hospitalisations for asthma}

Surgery reduced the number of hospitalisations for asthma from seven admissions in the pre-operative 12 months to two post-operatively $(\mathrm{p}<0.05$ (Wilcoxon signed-rank test)). Conversely, the medical treatment of CRS reduced this from five admissions to one ( $\mathrm{p}<0.05$ (Wilcoxon signed-rank test)). The difference between the surgical and medical groups was insignificant ( $p>0.05$ (Mann-Whitney test)).

\section{Objective measurements}

\section{Exhaled nitric oxide}

Levels of eNO decreased significantly, more so in the medical group, in which there were lower levels of eNO at 12 months than at 6 months in the total group $(p<0.01)$ and the polyp subgroup $(\mathrm{p}<0.05$; tables 2 and 3$)$. Among polyp patients, medical therapy reduced eNO levels more than surgery at 12 months $(\mathrm{p}<0.05)$.

\section{Forced expiratory volume in one second}

The 6- and 12-month FEV1 (\% pred) of the surgical group showed significant increases $(\mathrm{p}<0.05$; tables 2 and 3$)$.

In the total medical group, and also in its non-polypoid subgroup, the 6-month FEV1 (\% pred) improved significantly $(\mathrm{p}<0.01)$.

The 12-month FEV1 (\% pred) was significantly better in the total medical group and both subgroups. The difference between the 6- and 12-month FEV1 (\% pred) was significant in the medical subgroup with polyposis $(\mathrm{p}<0.05)$. This also

\begin{tabular}{|c|c|c|c|}
\hline \multirow[t]{2}{*}{ TABLE 2} & \multicolumn{3}{|c|}{$\begin{array}{l}\text { Change from baseline in objective lower airway } \\
\text { measurements at } 6 \text { months in chronic } \\
\text { rhinosinusitis patients }\end{array}$} \\
\hline & Surgical group \% & Medical group \% & p-value ${ }^{\#}$ \\
\hline \multicolumn{4}{|l|}{ eNO } \\
\hline Total & $16.33 \pm 40.05(21)$ & $25.16 \pm 20.71$ (19) & $>0.05^{\circ}$ \\
\hline No polyposis & $23.83 \pm 38.14(9)$ & $26.68 \pm 19.48(9)$ & $>0.05^{\circ}$ \\
\hline Polyposis & $10.71 \pm 42.16$ & $23.80 \pm 22.72(10)$ & $>0.05^{\circ}$ \\
\hline \multicolumn{4}{|l|}{ FEV1 \% pred } \\
\hline Total & $3.31 \pm 7.90(21)$ & $3.94 \pm 4.53(19)$ & $>0.05^{\circ}$ \\
\hline No polyposis & $6.40 \pm 9.36(9)$ & $5.31 \pm 4.69$ (9) & $>0.05^{\circ}$ \\
\hline Polyposis & $0.99 \pm 5.50(12)$ & $2.71 \pm 4.23(10)$ & $>0.05$ \\
\hline \multicolumn{4}{|l|}{ PEF } \\
\hline Total & $4.03 \pm 12.49(21)$ & $4.59 \pm 10.49(19)$ & $>0.05^{\circ}$ \\
\hline No polyposis & $8.56 \pm 15.28(9)$ & $8.06 \pm 12.39(9)$ & $>0.05^{\circ}$ \\
\hline Polyposis & $0.64 \pm 9.20(12)$ & $1.47 \pm 7.81(10)$ & $>0.05$ \\
\hline
\end{tabular}

Data are presented as mean $\pm S D(n)$. eNO: exhaled nitric oxide; FEV1: forced expiratory volume in one second; \% pred: percentage of the predicted value; PEF: peak expiratory flow. ${ }^{\#}$ : two-sample test; ${ }^{\text {": }}$ : Mann-Whitney test. differed significantly from its corresponding surgical subgroup $(\mathrm{p}<0.05)$.

\section{Peak expiratory flow}

Despite the fact that there was an improvement in PEF in all groups in the follow-up settings, this reached significance only in the total medical group and medical non-polypoid subgroup (tables 2 and 3).

\section{DISCUSSION}

This first prospective randomised study demonstrates that both medical and surgical treatment of CRS are associated with improvement in concomitant asthma. There was a correlation between changes in symptoms in the upper respiratory tract and asthma symptoms and control.

Medical therapy was superior in some respects; asthma control remained highly improved at 12 months, whereas, following surgery, the 12-month values were less significantly improved than those at 6 months. The difference between the medical and surgical groups was significant for eNO and FEV1 in polypoid CRS. eNO is a sensitive noninvasive test of lower airways inflammation, increasing during exacerbations and decreasing during recovery and in response to antia-sthmatic anti-inflammatory treatments [23, 24], and also correlating with sputum eosinophil numbers [25].

The effectiveness of medical treatment could be due to indirect effects. The combined use of long-term erythromycin and glucocorticoids seems to provide control of the inflammatory reaction in the upper airway by decreasing the microbiological load, reducing the number of leukocytes, and downregulating a wide range of cytokines and inflammatory mediators [26]. Upper airway inflammation may affect the lungs via several mechanisms, including systemic activation of eosinophil precursors from bone marrow [27].

\begin{tabular}{|c|c|c|c|}
\hline \multirow[t]{2}{*}{ TABLE 3} & \multicolumn{3}{|c|}{$\begin{array}{l}\text { Change from baseline in objective lower airway } \\
\text { measurements at } 12 \text { months in chronic } \\
\text { rhinosinusitis patients }\end{array}$} \\
\hline & Surgical group \% & Medical group \% & p-value ${ }^{\#}$ \\
\hline \multicolumn{4}{|l|}{ eNO } \\
\hline Total & $20.05 \pm 33.32(21)$ & $36.89 \pm 18.07(17)$ & $>0.05$ \\
\hline No polyposis & $28.97 \pm 34.80(9)$ & $32.30 \pm 20.50(9)$ & $>0.05$ \\
\hline Polyposis & $13.36 \pm 31.99(12)$ & $42.06 \pm 14.44(8)$ & $<0.05$ \\
\hline \multicolumn{4}{|l|}{$\mathrm{FEV}_{1} \%$ pred } \\
\hline Total & $3.95 \pm 7.87(21)$ & $5.88 \pm 4.05(17)$ & $>0.05^{\circ}$ \\
\hline No polyposis & $6.77 \pm 10.13$ & $5.10 \pm 3.72(9)$ & $>0.05^{\circ}$ \\
\hline Polyposis & $1.83 \pm 5.15(12)$ & $6.76 \pm 4.47(8)$ & $<0.05$ \\
\hline \multicolumn{4}{|l|}{ PEF } \\
\hline Total & $4.14 \pm 12.30$ & $7.59 \pm 12.00(17)$ & $>0.05^{\circ}$ \\
\hline No polyposis & $8.39 \pm 15.95(9)$ & $8.87 \pm 14.88$ & $>0.05^{\circ}$ \\
\hline Polyposis & $0.96 \pm 8.04(12)$ & $6.16 \pm 8.49(8)$ & $>0.05$ \\
\hline
\end{tabular}

Data are presented as mean \pm SD $(n)$. eNO: exhaled nitric oxide; FEV1: forced expiratory volume in one second; \% pred: percentage of the predicted value; PEF: peak expiratory flow. " : two-sample test; ": Mann-Whitney test. 
Alternatively, macrolides may play a direct role in control of asthma through their antibacterial, anti-inflammatory and glucocorticoid-sparing properties. The antibacterial properties of erythromycin include action against atypical pathogens such as Mycoplasma pneumoniae and Chlamydia pneumoniae, which have been implicated in the pathogenesis of asthma [28]. The anti-inflammatory properties of erythromycin were thought to play the main role in the control of the asthmatic inflammatory response, especially through inhibition of the eosinophilic response and reduction of levels of cytokines and reactive oxygen species [29-31]. Erythromycin was also reported to attenuate bronchial hyperresponsiveness in patients with bronchial asthma, probably through its inhibitory action on superoxide production and chemotaxis of neutrophils [32]. Erythromycin may also be helpful in asthma management, through protection of the ciliated airway epithelium from the action of bioactive phospholipids [33], reduction of mucus production [34] and improvement of the biophysical properties of mucus [35]. Finally, it has been suggested that erythromycin inhibits glucocorticoid clearance and enhances the effect of steroid therapy on asthma [36].

Surgically treated patients showed a trend for improvement in both subjective and objective lower airway measurements. This reached significance for all parameters except asthma score, use of corticosteroid inhalers and PEF. There were changes which did not reach significance in the operated polypoid and non-polypoid subgroups, which did not differ from each other.

Surgery appears to have a negative effect on asthma in a small subgroup of CRS patients. The present study included two $(8.7 \%)$ patients whose lower airway manifestations worsened after surgery. Both showed increased use of medication, elevated eNO levels and reduced FEV1 and PEF. Both also showed subjective and objective improvement in their upper respiratory tract manifestations post-operatively. Other authors have reported an $18-40 \%$ subjective worsening of asthma or precipitation of the first attack of asthma [9, 10, 37] after sinus surgery. There is a suggestion that patients with nasal polyposis are the most likely group to experience asthma exacerbations post-operatively. The present study does not support this observation, since there was a general, although nonsignificant, subjective and objective tendency for asthma improvement in the CRS with polyposis surgical group. Secondly, there was no significant difference between the CRS surgical groups with and without polyps. Thirdly, the only patient with new asthma after surgery had no polyps. A previous study demonstrated no major differences in outcomes between CRS with and without polyposis [38]. However, the present study suggests that medical treatment for CRS with polyposis is more effective in improving asthma.

Surgical trauma may induce a change in the upper respiratory tract cytokine profile, or cytokine release, with the ability to trigger or aggravate asthma in a special subgroup of patients. BOLARD et al. [39] demonstrated that microscopic intranasal sphenoethmoidectomy for CRS with polyposis altered the cytokine profile in nasal secretions, with significantly higher levels of interleukin- $8,-10$ and $-1 \beta$ than in the medically treated or untreated groups. HigASHI et al. [40] have recently shown that sinus surgery increases urinary leukotriene $\mathrm{E}_{4}$ levels and postulated that upper respiratory tract mucosal inflammation contributes to the burden of inflammatory mediators capable of causing both upper and lower respiratory tract effects via the systemic circulation. It is possible that, during surgical intervention, leukotrienes are released. Therefore, patients undergoing upper respiratory tract sinus surgery should receive oral corticosteroids, and possibly anti-leukotrienes, perioperatively.

\section{Conclusion}

Both medical and surgical therapy of chronic rhinosinusitis improved the clinical course of asthma, with medical treatment being superior to surgical in chronic rhinosinusitis with polyposis.

\section{REFERENCES}

1 Annesi-Maesano I. Epidemiological evidence of the occurrence of rhinitis and sinusitis in asthmatics. Allergy 1999; 54: Suppl. 57, 7-13.

2 Berman SZ, Mathison DA, Stevenson DD, Usselman JA, Shore S, Tan EM. Maxillary sinusitis and bronchial asthma: correlation of roentgenograms, cultures, and thermograms. J Allergy Clin Immunol 1974; 53: 311-317.

3 Rachelefsky GS, Goldberg M, Katz RM, et al. Sinus disease in children with respiratory allergy. J Allergy Clin Immunol 1978; 61: 310-314.

4 Pfister R, Lutolf M, Schapowal A, Glatte B, Schmitz M, Menz G. Screening for sinus disease in patients with asthma: a computed tomography-controlled comparison of A-mode ultrasonography and standard radiography. $J$ Allergy Clin Immunol 1994; 94: 804-809.

5 ten Brinke A, Grootendorst DC, Schmidt JT. Chronic sinusitis in severe asthma is related to sputum eosinophilia. J Allergy Clin Immunol 2002; 109: 621-626.

6 Jankowski R, Moneret-Vautrin DA, Goetz R, Wayoff M. Incidence of medico-surgical treatment for nasal polyps on the development of associated asthma. Rhinology 1992; 30: 249-258.

7 Senior BA, Kennedy DW. Management of sinusitis in the asthmatic patient. Ann Allergy Asthma Immunol 1996; 77: 6-15.

8 Stammberger H. Asthma and sinus disease. In: Stammberger $\mathrm{H}$, ed. Functional Endoscopic Sinus Surgery. The Messerklinger Technique. Philadelphia, B.C. Decker, 1991; pp. 453-458.

9 Francis C. Prognosis of operations for removal of nasal polyps in asthma. Practitioner 1929; 123: 272-278.

10 Samter M, Lederer FL. Nasal polyps: their relationship to allergy, particularly bronchial asthma. Med Clin N Am 1958; 42: 175-179.

11 Brown BL, Harner SG, Van Dellen RG. Nasal polypectomy in patients with asthma and sensitivity to aspirin. Arch Otolaryngol 1979; 105: 413-416.

12 Goldstein MF, Grundfast SK, Dunsky EH, Dvorin DJ, Lesser R. Effect of functional endoscopic sinus surgery on bronchial asthma outcomes. Arch Otolaryngol Head Neck Surg 1999; 125: 314-319.

13 Slavin RG. Relationship of nasal disease and sinusitis to bronchial asthma. Ann Allergy 1982; 49: 76-79.

14 Lamblin C, Brichet A, Perez T, Darras J, Tonnel AB, Wallaert B. Long-term follow-up of pulmonary function in 
patients with nasal polyposis. Am J Respir Crit Care Med 2000; 161: 406-413.

15 Lund VJ, Kennedy DW. Quantification for staging sinusitis. Ann Otol Rhinol Laryngol Suppl 1995; 167: 17-21.

16 Barnes PJ, Godfrey S. Asthma. 2nd Edn. London, Martin Dunitz, 2000.

17 Ware JE Jr, Sherbourne CD. The MOS 36-item short-form health survey (SF-36). I. Conceptual framework and item selection. Med Care 1992; 30: 473-483.

18 Bateman ED, Frith LF, Braunstein GL. Achieving guideline based asthma control: does the patient benefit? Eur Respir J 2002; 20: 588-595.

19 Kharitonov S, Alving K, Barnes PJ. Exhaled and nasal nitric oxide measurements: recommendations. Eur Respir J 1997; 10: 1683-1693.

20 European Respiratory Society. Standardised lung function testing. Official statement of the European Respiratory Society. Eur Respir J 1993; 6: Suppl. 16, 1-100.

21 Stammberger H. Surgical technique. In: Stammberger H, ed. Functional Endoscopic Sinus Surgery. The Messerklinger Technique. Philadelphia, B.C. Decker, 1991; pp. 283-320.

22 Ragab S, Lund VJ, Scadding GK. Evaluation of medical and surgical management of chronic rhinosinusitis: a prospective randomized controlled trial. Laryngoscope 2004; 114: 923-930.

23 Massaro AF, Gaston B, Kita D, Fanta C, Stamler JS, Drazen JM. Expired nitric oxide levels during treatment of acute asthma. Am J Respir Crit Care Med 1995; 152: 800-803.

24 Kharitonov SA, Yates DH, Barnes PJ. Inhaled glucocorticoids decrease nitric oxide in exhaled air of asthmatic patients. Am J Respir Crit Care Med 1996; 153: 454-457.

25 Warke TJ, Fitch PS, Brown V, et al. Exhaled nitric oxide correlates with airway eosinophils in childhood asthma. Thorax 2002; 57: 383-387.

26 Scadding GK. Medical management of chronic rhinosinusitis. Immunol Allergy Clin North Am 2004; 24: 103-109.

27 Denburg JA, Keith PK. Systemic aspects of chronic rhinosinusitis. Immunol Allergy Clin North Am 2004; 24: 87-102.

28 Martin RJ, Kraft M, Chu HW, Berns EA, Cassell GH. A link between chronic asthma and chronic infection. J Allergy Clin Immunol 2001; 107: 595-601.

29 Takizawa H, Desaki M, Ohtoshi T, et al. Erythromycin and clarithromycin attenuate cytokine-induced endothelin-1 expression in human bronchial epithelial cells. Eur Respir J 1998; 12: 57-63.

30 Konno S, Adachi M, Asano K, Kawazoe T, Okamoto K, Takahashi T. Influences of roxithromycin on cell-mediated immune responses. Life Sci 1992; 51: L107-L112.

31 Noma T, Aoki K, Hayashi M, Yoshizawa I, Kawano Y. Effect of roxithromycin on $\mathrm{T}$ lymphocyte proliferation and cytokine production elicited by mite antigen. Int Immunopharmacol 2001; 1: 201-210.

32 Miyatake H, Taki F, Taniguchi H, Suzuki R, Takagi K, Satake T. Erythromycin reduces the severity of bronchial hyperresponsiveness in asthma. Chest 1991; 99: 670-673.

33 Feldman C, Anderson R, Theron AJ, Ramafi G, Cole PJ, Wilson R. Roxithromycin, clarithromycin, and azithromycin attenuate the injurious effects of bioactive phospholipids on human respiratory epithelium in vitro. Inflammation 1997; 21: 655-665.

34 Tamaoki J, Takeyama K, Yamawaki I, Kondo M, Konno K. Lipopolysaccharide-induced goblet cell hypersecretion in the guinea pig trachea: inhibition by macrolides. Am J Physiol 1997; 272: L15-L19.

35 Rhee CS, Majima Y, Arima S, et al. Effects of clarithromycin on rheological properties of nasal mucus in patients with chronic sinusitis. Ann Otol Rhinol Laryngol 2000; 109: 484-487.

36 LaForce CF, Szefler SJ, Miller MF, Ebling W, Brenner M. Inhibition of methylprednisolone elimination in the presence of erythromycin therapy. J Allergy Clin Immunol 1983; 72: 34-39.

37 Nakamura H, Kawasaki M, Higuchi Y, Takahashi S. Effects of sinus surgery on asthma in aspirin triad patients. Acta Otolaryngol 1999; 119: 592-598.

38 Dunlop G, Scadding GK, Lund VJ. The effect of endoscopic sinus surgery on asthma: management of patients with chronic rhinosinusitis, nasal polyposis, and asthma. Am J Rhinol 1999; 13: 261-265.

39 Bolard F, Gosset P, Lamblin C, Bergoin C, Tonnel AB, Wallaert B. Cell and cytokine profiles in nasal secretions from patients with nasal polyposis: effects of topical steroids and surgical treatment. Allergy 2001; 56: 333-338.

40 Higashi N, Taniguchi M, Mita $\mathrm{H}$, et al. Clinical features of asthmatic patients with increased urinary leukotriene $\mathrm{E}_{4}$ excretion (hyperleukotrienuria): involvement of chronic hyperplastic rhinosinusitis with nasal polyposis. J Allergy Clin Immunol 2004; 11: 277-283. 